\title{
Orientation and presence of epithelium are key to endotoxin-induced neutrophil migration
}

\author{
F.M.G. Peralta*, T.B. Casale*+
}

Orientation and presence of epithelium are key to endotoxin-induced neutrophil migration. F.M.G. Peralta, T.B. Casale. (OERS Journals Ltd 1998.

ABSTRACT: The mechanisms by which endotoxins mediate neutrophil transepithelial migration and lung inflammation are unclear. It was hypothesized that both the presence and orientation of epithelial cells are critical to endotoxin-induced neutrophil migration.

Neutrophil migration was compared through naked filters and filters with A549 lung epithelial monolayers grown on the upper and lower surface of permeable filters to simulate the apical and basal directional movement of neutrophils, respectively. The endotoxin, Pseudomonas aeruginosa lipopolysaccharide, was placed below the filter, acting as either a basal or an apical stimulus.

Endotoxin without serum failed to stimulate neutrophil migration. In the presence of $1 \%$ human serum, endotoxin-induced neutrophil migration through naked filters was dose dependent. Endotoxin-induced neutrophil migration across A549 monolayers was minimal when the monolayers were cultured on the upper surface of the filters (basal stimulus). In contrast, neutrophil transepithelial migration was much greater and dependent on both dose and time when the monolayer was cultured on the lower surface of the filter (basal to apical neutrophil directional movement). Furthermore, enhanced neutrophil transepithelial migration was greater with an apical than with a basal stimulus. Endotoxin-induced neutrophil transepithelial migration was markedly inhibited $(>95 \%)$ by actinomycin D pretreatment of the monolayers, suggesting the necessity for intact protein synthesis capacity of the A549 cells.

Thus, both the presence and orientation of airway epithelium are key in supporting endotoxin-mediated lung neutrophilic responses.

Eur Respir J 1998; 11: 1053-1059.

The airway epithelium forms a complex interface between the host and the environment. The epithelium performs important homeostatic functions including gas transport, microbial defence, secretion, mucociliary clearance, ion and fluid transport, cellular repair and proliferation, as well as barrier protection [1]. Over the last several years important information has emerged suggesting that the airway epithelium also contributes to the regulation of local inflammation and immune responses. Relevant epithelial functions to inflammatory processes include the metabolism and catabolism of mediators and cytokines and the expression of key adhesion molecules.

Airway inflammation in endotoxin-induced lung disorders such as bronchitis, bacterial pneumonias, cystic fibrosis and organic dust-induced lung diseases are characterized by the infiltration of neutrophils into the lungs and airways $[1,2]$. It is believed that the initiation and activation of the neutrophil response is mediated by cellto-cell communication networks among immune and nonimmune cells stimulated by endotoxin in the airways [3]. Little, if anything, is known about the exact role played by pulmonary epithelial cells in modulating endotoxin-induced neutrophil migration.

Studies examining the mechanisms involved in stimulated neutrophil transepithelial migration have generally
*Dept of Internal Medicine, University of Iowa, Iowa City, IA, USA and Veterans Administration Medical Center, Iowa City, IA, USA. +Nebraksa Medical Research Institute, Papillion, NE, USA.

Correspondence: T.B. Casale

Nebraska Medical Research Institute 401 East Gold Coast Road, Suite 124 Papillion

NE 68046-4796

USA

Fax: 4025969967

Keywords: Chemotaxis

endotoxin

epithelium

lung

Received: July 101997

Accepted after revision January 201998

Supported in part by a Veterans Administration Merit Review and Clinical Investigator (Dr Casale) Awards. been conducted with the lung epithelial cells cultured on top of permeable filters $[4,5]$. However, neutrophil transepithelial migration in the respiratory tract during endotoxin-associated airway diseases is likely to occur predominantly in a basal to apical, rather than apical to basal direction. It was therefore questioned whether there might be a difference in neutrophil transepithelial migration patterns if the neutrophils moved through the lung epithelium in an apical versus basal direction in response to endotoxin.

To determine the role of cellular monolayer orientation on endotoxin-induced neutrophil migration, an in vitro model system was constructed wherein A549 type II-like alveolar lung cells were cultured on the lower and upper surfaces of permeable Transwell® filters. A549 cells grown on the lower surface of the filters were apically stimulated, while A549 cells grown on the upper surface of the filters were basally stimulated when the endotoxin was placed in the bottom of the wells. Because of its clinical importance in many gram-negative inflammatory lung conditions, Pseudomonas aeruginosa lipopolysaccharide (LPS) was utilized as the neutrophil chemoattractant. The presence and orientation of the epithelium, and thereby the directional movement of the neutrophils, significantly 
influen-ced neutrophil migration across pulmonary epithelial cells.

\section{Materials and methods}

\section{Reagents}

Bovine serum albumin (BSA), phosphate-buffered saline (PBS), $P$. aeruginosa serotype 10 LPS and collagen (bovine placental type IV) were purchased from Sigma Chemical Co. (St Louis, MO, USA). Hypaque M-90\% was a gift from Winthrop Pharmaceuticals (New York, NY, USA). Ham's F12K was purchased from Irvine (CA, USA). Foetal calf serum (FCS), trypsin, ethylene diamine tetra-acetic acid (EDTA), antibiotics and Hank's balanced salt solution (HBSS) were purchased from the University of Iowa Cancer Center (Iowa City, IA, USA). Transwell@ tissue-culture plates were purchased from Costar (Cambridge, MA, USA). Chromium-51, $\mathrm{Na}_{2} \mathrm{CrO}_{4}\left({ }^{51} \mathrm{Cr}\right)$ was purchased from New England Nuclear Co. (Boston, MA, USA).

\section{Cell culture}

A549 human type II-like epithelial lung cells (A549) [6] (passage 76) were purchased from the American Type Culture Collection (Rockville, MD, USA). A549 cells were grown as monolayers in tissue-culture flasks incubated in $100 \%$ humidity and $5 \% \mathrm{CO}_{2}$ at $37^{\circ} \mathrm{C}$ in Ham's F12K medium supplemented with $10 \% \mathrm{FCS}$, penicillin $\left(20 \mathrm{U} \cdot \mathrm{mL}^{-1}\right)$ and streptomycin $\left(20 \mu \mathrm{g} \cdot \mathrm{mL}^{-1}\right)$. Culture flasks and filters were treated with collagen type IV $\left(50 \mu \mathrm{g} \cdot \mathrm{mL}^{-1}\right)$ for at least $30 \mathrm{~min}$ at $37^{\circ} \mathrm{C}$, and rinsed with HBSS. Cell monolayers in tissue-culture flasks were harvested with trypsin $(0.25 \%)$ and EDTA $(0.1 \%)$ in PBS, centrifuged at low speed (250 g, $5 \mathrm{~min})$ and resuspended in fresh medium before culture on permeable filters in Transwell@ tissue-culture plates. Cells $\left(1.5 \times 10^{6} \cdot \mathrm{mL}^{-1}\right)$ in $100 \mu \mathrm{L}$ were grown to confluence on the upper or lower surface of these filters in Transwell@ plates over 3-5 days as previously described $[4,5,7,8]$ using the same conditions outlined for the flasks (fig. 1). Cells grown on the lower surface were first placed on inverted collagen-coated filters and incubated for $2 \mathrm{~h}$ at $37^{\circ} \mathrm{C}$. The filters were then overturned (righted) and placed in the lower well of the Transwell@. Monolayer integrity was assessed by microscopy, alb-umin permeability, transmonolayer electrical

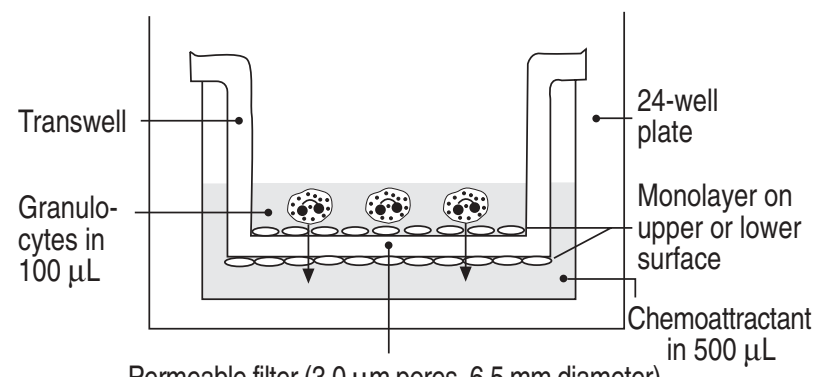

Fig. 1. - Diagram of the chemotaxis chamber illustrating how the experiments were conducted. resistance and negative (buffer) controls as previously described [7]. Monolayers were microscopically examined before use for confluency. Albumin permeability was negligible and equivalent to monolayers cultured on the upper versus the lower surface of the filters. Transmonolayer electrical re-sistance was the same for monolayers grown on the upper versus the lower surface of the filters. The 24 well Transwell@ plates are separated into upper and lower chambers by a $6.5 \mathrm{~mm}$ diameter polycarbonate filter with a $3.0 \mu \mathrm{m}$ pore size.

\section{Isolation of neutrophils and chromium labelling}

Neutrophils were isolated from $0.2 \%$ EDTA-anticoagulated whole blood collected by venipuncture. Neutrophils were obtained using a modification of the density gradient technique (1.095 Hypaque-Ficoll) described by FerRante and THONG [9]. The isolated neutrophils were washed once with HBSS without $\mathrm{Ca}^{2+}$ and $\mathrm{Mg}^{2+}$. Neutrophils were then resuspended in $4 \mathrm{~mL}$ of $\mathrm{HBSS}$ without $\mathrm{Ca}^{2+}$ and $\mathrm{Mg}^{2+}$ and residual red cells were lysed using $1 \%$ ammonium oxalate ( $w / v$ in $\mathrm{H}_{2} \mathrm{O}$ ). The neutrophils were then washed again in HBSS without $\mathrm{Ca}^{2+}$ and $\mathrm{Mg}^{2+}$ before performing cell counts. Viability was determined by trypan blue exclusion. The isolated neutrophils were at least $98 \%$ pure and $99 \%$ viable.

Isolated neutrophils were labelled with ${ }^{51} \mathrm{Cr}$ before being placed in the chemotactic chambers by using a modification of the procedure described by GALLN et al. [10]. Neutrophils at concentrations of $15-45 \times 10^{6}$ cells $\cdot \mathrm{mL}^{-1}$ were incubated in $\mathrm{Ca}^{2+} / \mathrm{Mg}^{2+}$-free HBSS with $0.5 \mathrm{mCi}$ of ${ }^{51} \mathrm{Cr}\left(5 \mathrm{mCi} \cdot \mathrm{mL}^{-1}\right)$ at $37^{\circ} \mathrm{C}$ for $1 \mathrm{~h}$ with vigorous mixing. The labelling was terminated at the end of the incubation period by diluting the cells to $50 \mathrm{~mL}$ with HBSS without $\mathrm{Ca}^{2+}$ and $\mathrm{Mg}^{2+}$. The neutrophils were subsequently washed three times in $\mathrm{Ca}^{2+} / \mathrm{Mg}^{2+}$-free HBSS before resuspension in $\mathrm{HBSS}$ with $0.2 \% \mathrm{BSA}, \mathrm{Ca}^{2+}$ and $\mathrm{Mg}^{2+}$. The cells were resuspended at $1.5 \times 10^{7} \cdot \mathrm{mL}^{-1}$ before use. Aliquots of the cell suspension were removed and assayed for total counts and unbound ${ }^{51} \mathrm{Cr}$ to determine the cell-associated counts per minute (cpm) as described by GaLIN et al. [10].

\section{Neutrophil migration}

Neutrophil migration through cell monolayers cultured on filters in either orientation was investigated using the 24-well tissue-culture-treated Transwell ${ }^{\circledR}$ plates as previously described $[4,5,7,8]$. Then, $1-1.5 \times 10^{6}{ }^{51} \mathrm{Cr}$-labelled neutrophils in $100 \mu \mathrm{L}$ of buffer were placed in the upper chamber, above the filter/monolayer or monolayer/filter complex. LPS in $500 \mu \mathrm{L}$ HBSS with $1 \%$ human serum, was placed in the lower chambers. Buffer with $1 \%$ human serum was placed in lower chambers as a negative control in each experiment. The negative control samples used barriers that corresponded directly to the experimental samples (e.g. A549 monolayers on the upper surface of filters with LPS and buffer as experimental and negative control samples). Formyl-methionyl-leucyl-phenylalanine (FMLP) was used as a positive control for each experiment. Each variable was tested in triplicate. The plates were incubated at $37^{\circ} \mathrm{C}$ in $5 \% \mathrm{CO}_{2}$ and $100 \%$ humidity for $3,6,18$ and $24 \mathrm{~h}$ in both the dose-response and timecourse experiments. Both barriers (filter/monolayer and monolayer/filter) were tested simultaneously with the same 
donor for each of the experiments. The degree of neutrophil migration was determined by mixing the lower chamber contents $(500 \mu \mathrm{L})$ with $300 \mu \mathrm{L}$ of $2 \%(\mathrm{v} / \mathrm{v})$ Triton $\mathrm{X}-100$ in $\mathrm{H}_{2} \mathrm{O}$, collecting the fluid, and then counting in a gamma counter to determine cpm. The data were expressed as the percentage net stimulated migration (NSM) using the formula:

$$
\begin{gathered}
\text { \% NSM }=(\mathrm{cpm} \text { experiment sample })- \\
(\mathrm{cpm} \text { negative control sample }) \times 100 \\
\text { total } \mathrm{cpm} \text { added to chamber }
\end{gathered}
$$

The cpm measured in the negative control (HBSS-human serum) samples were generally less than $5 \%$ of the total cpm added to the top chamber regardless of whether the monolayers were cultured on the upper or the lower surface of the filters.

Figure 1 shows a diagram of the chemotaxis chamber illustrating how the experiments were conducted.

\section{Results}

\section{Endotoxin-induced neutrophil migration across naked fil- ters}

The NSM of neutrophils across naked filters was determined utilizing $P$. aeruginosa serotype 10 LPS (endotoxin) as the chemoattractant. Preliminary results showed that endotoxin by itself was unable to stimulate neutrophil chemotaxis. When $1 \%$ human serum was added, clinically relevant amounts of LPS induced neutrophil migration across naked filters [11-14]. The serum was added to provide soluble CD14 and LPS binding protein (LPS-BP) as well as other putatively necessary cofactors [15]. Significant dose-responsive neutrophil migration was observed with endotoxin doses between 1.0 and $0.01 \mu \mathrm{g} \cdot \mathrm{mL}^{-1}$ at both 3 and $6 \mathrm{~h}$ (pð0.05 by Bonferroni t-test; fig. 2). There were no significant differences in NSM values when comparing 3 and $6 \mathrm{~h}$ incubation periods at similar endotoxin concentrations.

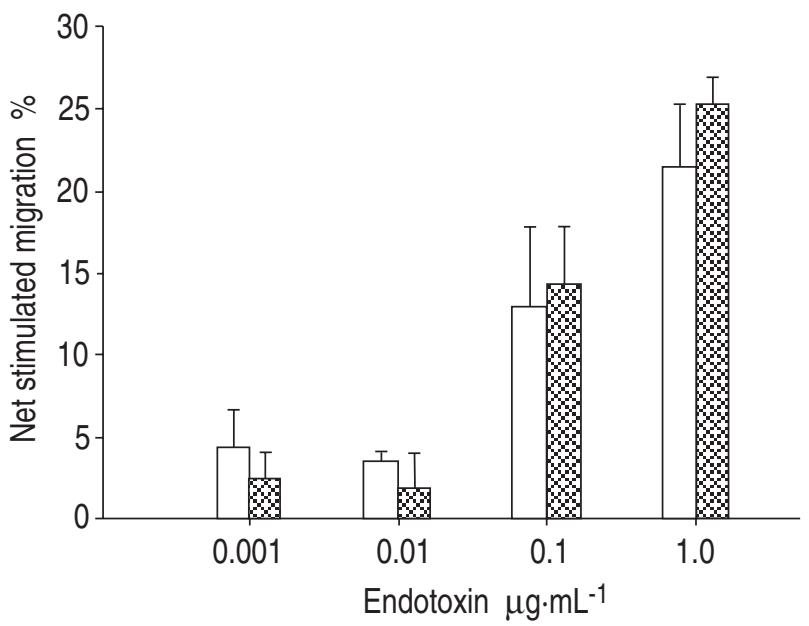

Fig. 2. - Dose-response of endotoxin-induced neutrophil migration across naked filters at $3 \mathrm{~h}(\square)$ and $6 \mathrm{~h}(\boldsymbol{\beta})$ ). Results represent means \pm SEM of net stimulated migration (NSM) from six experiments with each variable performed in triplicate. There were no significant differences in NSM values between the 3 and $6 \mathrm{~h}$ incubation times.
Effect of pulmonary epithelial cell monolayer orientation on endotoxin-induced neutrophil migration

To determine the role of cellular monolayer orientation a comparison was made of endotoxin-induced neutrophil migration through A549 cells cultured on the lower versus the upper surface of the Transwell@ filters. As with naked filter barriers, no significant migration was observed in the absence of $1 \%$ human serum (data not shown). Therefore, the remainder of the experiments were performed in the presence of $1 \%$ human serum. Very little neutrophil migration was observed through A549 monolayers cultured on the upper surface of the Transwell@ filters at either 3 or $6 \mathrm{~h}$ (fig. 3a and b, respectively). In contrast, significant neutrophil migration was observed through the A549 monolayers cultured on the lower surface (apical stimulation) (fig. 3). The neutrophil NSM was greater at 6 than at $3 \mathrm{~h}$ and was dose-responsive, especially at $6 \mathrm{~h}$.

To determine the effects of prolonged endotoxin stimulation on neutrophil transepithelial migration, a $24 \mathrm{~h}$ time-course experiment was performed with $1.0 \mu \mathrm{g} \cdot \mathrm{mL}^{-1}$ endotoxin. At 3, 6, 18 and $24 \mathrm{~h}$, endotoxin induced significantly more neutrophil migration across epithelial cell
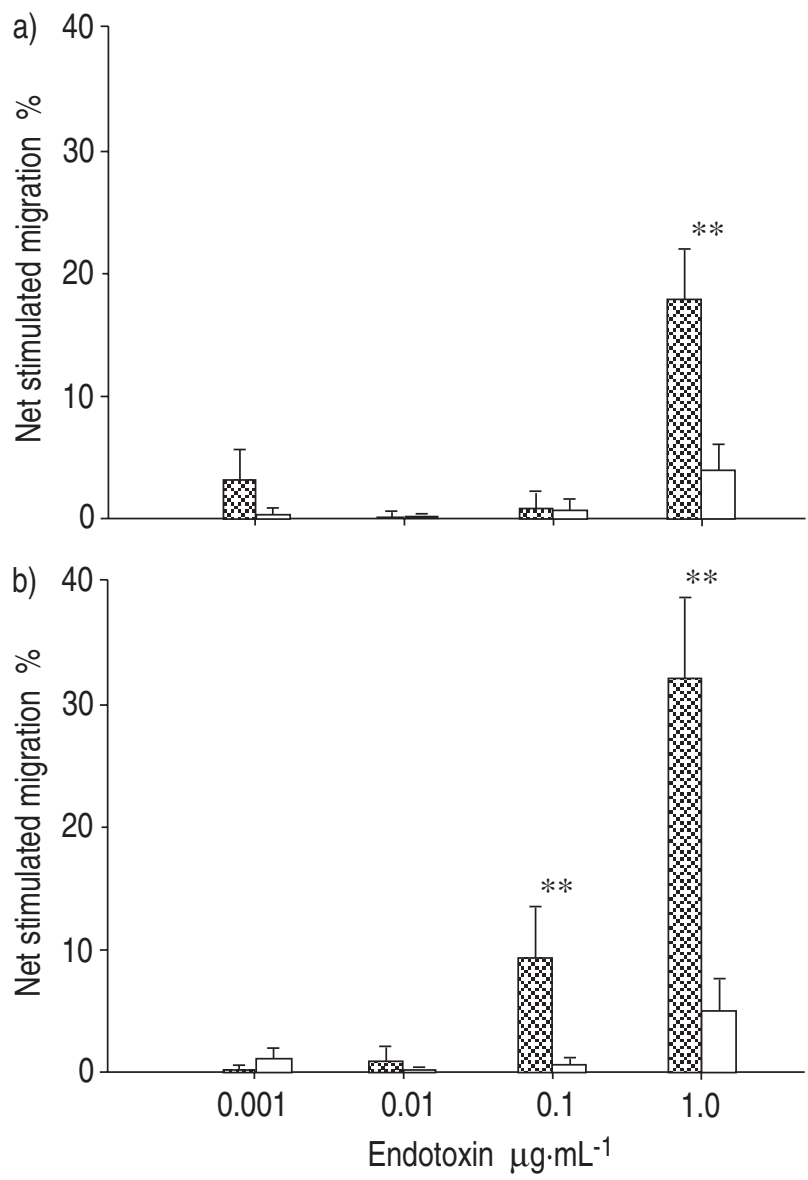

Fig. 3. - Effect of monolayer orientation and endotoxin dose on neutrophil migration. Dose-response of endotoxin-induced neutrophil migration across A549 monolayers grown on the lower surface ( $\infty$ ) versus the upper surface ( $\square$ ) of Transwell® filters at: a) $3 \mathrm{~h}$ and b) 6 $\mathrm{h}$. Results represent means \pm SEM of net stimulated migration from: a) five and b) six experiments with each variable performed in triplicate. There was significantly more neutrophil migration across epithelial monolayers grown on the lower versus the upper surface. **: pð0.01 by Bonferroni t-test. 


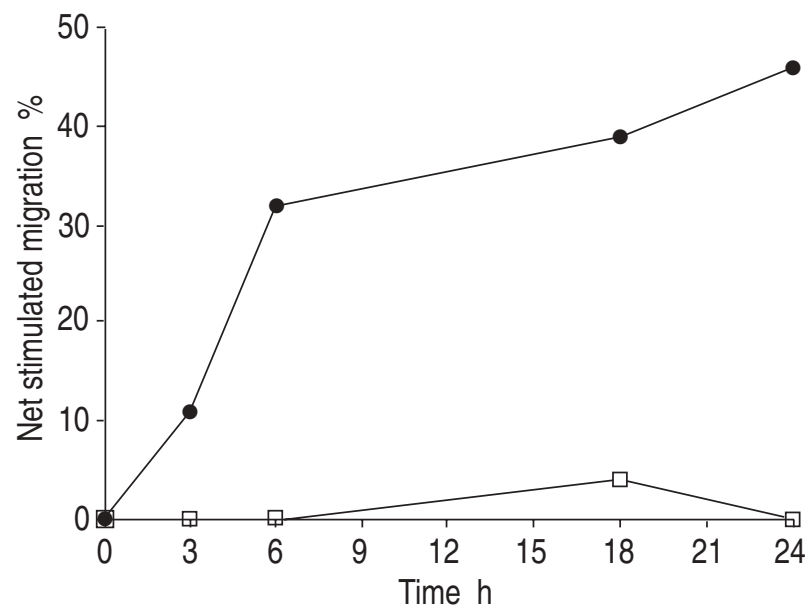

Fig. 4. - Effect of monolayer orientation and incubation time on endotoxin-induced neutrophil migration. Comparison between neutrophil migration across A549 monolayers grown on the lower surface (•) versus the upper surface ( $\square$ ) utilizing $1.0 \mu \mathrm{g} \cdot \mathrm{mL}^{-1}$ of endotoxin over $24 \mathrm{~h}$. There was significantly more neutrophil migration across epithelial monolayers stimulated apically at all time-points over the $24 \mathrm{~h}$ period, pð0.01 by Bonferroni t-test.

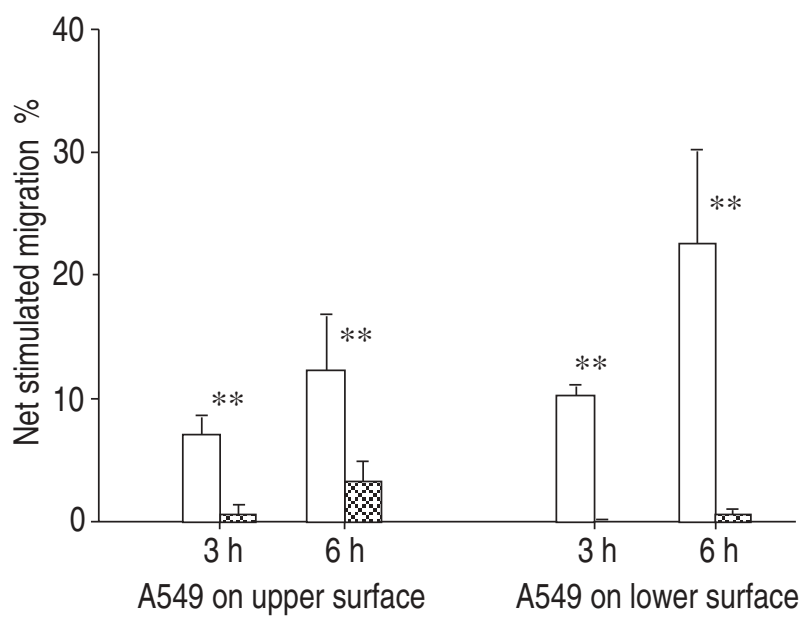

Fig. 5. - Effect of monolayer and endotoxin orientation on neutrophil migration. Neutrophil migration was examined through A549 monolayers grown on the upper surface versus the lower surface of Transwell@ filters with $1.0 \mu \mathrm{g} \cdot \mathrm{mL}^{-1}$ of endotoxin (in the presence of $1 \%$ serum) located either below ( $\square$ ) or above ( $\infty$ ) the filter/monolayer complex. Results represent means \pm SEM net stimulated migration from three experiments with each variable performed in triplicate. **: pð0.01 by Bonferroni t-test for endotoxin below versus above the filter/monolayer monolayers in the basal to apical than in the apical to basal direction (fig. 4). Indeed, throughout the $24 \mathrm{~h}$ period, minimal neutrophil transepithelial migration was obser-ved when monolayers were grown on the upper surface (basal stimulation).

Effect of monolayer and endotoxin orientation on neutrophil migration
A series of experiments was designed to examine whether the enhanced endotoxin-induced neutrophil NSM in a basal to apical direction was dependent on the directionality of the neutrophil migration or the polarity of the stimulus. A549 monolayers were grown on either the upper or lower surface of the Transwell® filters and neutrophil migration with endotoxin (in the presence of $1 \%$ serum) placed in the upper chamber was compared with that in the lower chamber (fig. 5). There was minimal neutrophil NSM across the monolayers when the endotoxin was placed above (on top of) the filter/monolayer complex. Neutrophil NSM was significantly greater across epithelial monolayers stimulated with endotoxin below the filters at 3 and $6 \mathrm{~h}$ regardless of monolayer orientation. Neutrophil migration was greatest when the A549 monolayers were grown on the lower surface of the filters and the endotoxin was placed in the lower chambers.

\section{Inhibitory effect of actinomycin D}

The A549 monolayers were pretreated with the mRNA synthesis metabolic inhibitor, actinomycin $\mathrm{D}$, as an indirect method to determine the need for intact monolayer cell protein synthesis in mediating neutrophil migration. A549 monolayers grown either on the upper or the lower surface of the filters were pretreated with $2 \mu \mathrm{g} \cdot \mathrm{mL}^{-1}$ actinomycin D or buffer for $30 \mathrm{~min}$ and washed thoroughly before a $6 \mathrm{~h}$ migration assay with $1.0 \mu \mathrm{g} \cdot \mathrm{mL}^{-1}$ of endotoxin. There was almost total inhibition $(>95 \%)$ of neutrophil migration across A549 monolayers pretreated with actinomycin D, regardless of the orientation of the monolayer (fig. 6). As before, more neutrophil migration was observed through A549 monolayers cultured on the lower than on the upper surface of the filters.

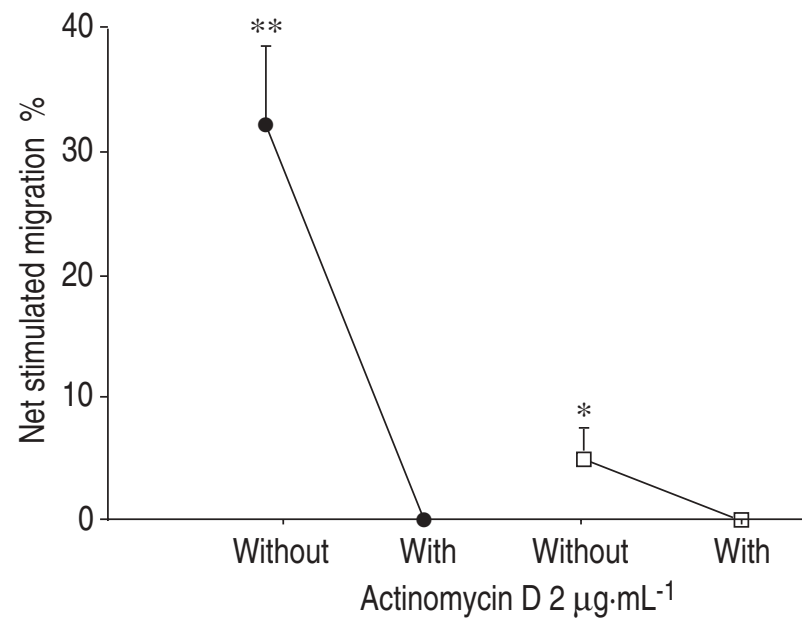

Fig. 6. - Inhibitory effect of actinomycin D on endotoxin-induced neu-

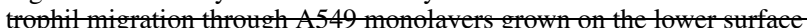
$(\bullet)$ or the upper surface $(\square)$ of the filters. Data are expressed as means 土SEM of net stimulated migration (NSM). *: pð0.05; **: pð0.01 by Bonferroni t-test. 


\section{FMLP-induced neutrophil migration}

FMLP was used as a positive control for these experiments. Neither the presence nor the orientation of the A549 epithelial monolayer significantly affected neutrophil NSM values. Furthermore, pretreatment of the A549 monolayers with actinomycin D did not affect FMLP-induced transepithelial migration in either an apical to basal or a basal to apical direction (table 1).

\section{Discussion}

Airway inflammation in endotoxin-associated lung disorders is characterized by the presence of neutrophils [1, 2]. The effect of the presence and orientation of pulmonary epithelial cells in modulating endotoxin-induced inflammatory processes and neutrophil cellular influx is poorly understood. To the authors' knowledge, there have been no published reports of studies examining endotoxin-induced neutrophil migration through respiratory epithelial cells in a manner analogous to the influx of neutrophils into the airway lumen (i.e. in a basal to apical direction). In an attempt to explain the complex interplay between neutrophils, pulmonary epithelial cell orientation and endotoxin in airway inflammation, an in vitro pulmonary epithelial monolayer model system was constructed (fig. 1). It should be noted that since the pulmonary epithelial cells used were A549 cells, these findings may be more representative of events occurring in the alveoli.

Using $P$. aeruginosa serotype 10 LPS as the chemoattractant, neutrophil migration across naked filters was first analysed. Initial results showed that in the presence of $1 \%$ human serum, neutrophils migrated in a dose-response pattern (fig. 2). Significant neutrophil migration was observed at doses of endotoxin measured in domestic water and commercial house-dust extracts [13, 14]. LPSinduced migration of neutrophils across naked filters was the same as or slightly greater than that across epithelium cultured on the lower surface of the filters and markedly greater than that across epithelium cultured on the upper surface of the filters. Thus, the epithelium did not enhance the ability of endotoxin to induce migration.

LPS was not able to induce neutrophil migration across naked filters or epithelial monolayers in the absence of serum. Although not definitively proven, the addition of serum was probably necessary to provide soluble CD14, LPS-BP and other serum components. The response of neutrophils to LPS is enhanced by complex formation

Table 1. - Formyl-methionyl-leucyl-phenylalanine (FLMP)induced neutrophil migration

\begin{tabular}{lcc}
\hline Barrier & $\begin{array}{c}\text { Pretreatment with } \\
\text { actinomycin D }\end{array}$ & NSM \\
Naked filters & Without & $50 \pm 2$ \\
A549 upper & Without & $45 \pm 2$ \\
surface & With & $46 \pm 1$ \\
A549 lower & Without & $44 \pm 1$ \\
surface & With & $45 \pm 2$
\end{tabular}

Results represent means \pm SEM of net stimulated migration (NSM) of neutrophils through the indicated barrier, which was pretreated with buffer or $2 \mathrm{mg} \cdot \mathrm{mL}^{-1}$ actinomycin $\mathrm{D}$ for $30 \mathrm{~min}$ and washed thoroughly before a $3 \mathrm{~h}$ migration assay with $10 \mathrm{nM}$ FMLP. with LPS-BP, septin or other serum factors which facilitate the recognition of LPS at the cell surface. Indeed, the efficient interaction of endotoxin with its CD14 receptor on both myeloid and epithelial cells is greatly enhanced by LPS-BP [15-20]. The capacity of LPS in the presence of serum to induce neutrophil migration may be due to the activation of neutrophils by LPS in complex with critical serum factors, such as CD14 and LPS-BP. Serum contains approximately $5-10 \mu \mathrm{g} \cdot \mathrm{mL}^{-1}$ of LPS-BP [20]. In the adult respiratory distress syndrome the full spectrum of plasma proteins has been demonstrated in bronchoalveolar lavage fluid [21]. Bronchoalveolar lavage fluid normally contains low levels of LPS-BP, but these levels may rise during episodes of endotoxin-associated lung inflammation [19, 20]. Thus, the combination of LPS and serum used in the present in vitro model system is likely to occur in the in vivo setting of endotoxin-induced lung neutrophilic responses.

All epithelial cells possess two distinct plasma membrane domains. The apical and basolateral domains differ in their protein and lipid composition, thus allowing a variety of vectorial functions in transport and secretion. Polarized secretion of inflammatory cytokines by epithelial cells may provide the directed stimulus necessary for neutrophils to move towards the site of infection [22, 23]. Our understanding of how the orientation of pulmonary epithelial cells affects endotoxin-induced neutrophil influx is somewhat deficient since only limited studies of this nature have been performed using intestinal, kidney and mesothelial cells [24-26].

In the studies reported herein, there was significantly more neutrophil migration across A549 monolayers at both 3 and $6 \mathrm{~h}$ incubation times when pulmonary epithelial cells were present on the lower surface of the filters (fig. 3). These data suggest that endotoxin-induced neutrophil transepithelial migration occurs preferentially in a basal to apical direction. By extending the observations over $24 \mathrm{~h}$, neutrophil migration across epithelial monolayers continued to show a preferential basal to apical directionality (fig. 4).

To further our understanding of the role of epithelial cell orientation on endotoxin-induced neutrophil transepithelial migration, $1 \mu \mathrm{g} \cdot \mathrm{mL}^{-1}$ of endotoxin was incubated above and below the filter while varying the monolayer orientation. There was significantly more neutrophil migration across the monolayers at both 3 and $6 \mathrm{~h}$ with endotoxin below the filters regardless of epithelial cell monolayer orientation. In addition, preferential movement of the neutrophils in a basal to apical fashion continued when epithelial cells were stimulated apically (fig. 5). Our findings agree with those of ZeLLEMAKER et al. [26] who showed preferential migration of neutrophils in the basal to apical direction during apical stimulation of mesothelial cells in an in vivo model of bacterial peritonitis. These experiments suggest that both the directionality of the neutrophil movement and the polarity of the stimulus are important in regulating endotoxin-induced neutrophil responses in the lung.

The marked inhibitory effects of actinomycin D on endotoxin-induced transepithelial migration confirm the importance of the epithelium in regulating endotoxinassociated airway inflammation (fig. 6). Regardless of the orientation of the monolayer, endotoxin-induced neutrophil migration is dependent on the intact protein synthesis 
capacity of the A549 cells. In contrast, neither epithelial cell orientation nor actinomycin D pretreatment had an effect on FMLP-induced neutrophil transepithelial migration. It is likely that the epithelium plays a more passive role in neutrophil transepithelial migration induced by a potent chemoattractant, such as FMLP.

It is becoming more evident that epithelial cells have evolved in their ability to regulate an inflammatory response to pathogens or endotoxins. Airway epithelial cells can initiate inflammatory cascades and participate in local cytokine networking in endotoxin-induced lung inflammation $[1,27]$. The mechanisms involved in endotoxinenhanced neutrophil transepithelial migration in a basal to apical direction were not addressed by these studies. The present data, however suggest several possible mechanisms including the polarized expression of key adhesion molecules and/or production of secondary peptide chemoattractants. Both the expression of adhesion molecules [28] and the production of peptide chemoattractants are inhibitable by actinomycin D [4, 5].

It has been shown previously that endotoxin can cause lung epithelial cells to express adhesion molecules, including intracellular adhesion molecule (ICAM)-1 [29]. Because of the interposed filter, this study could not determine whether these cytokines induced the expression of adhesion molecule in a polarized fashion. Moreover, the authors are unaware of any studies examining this possibility using analogous systems. None the less, protein trafficking pathways leading to an apical or a basolateral expression of proteins have been demonstrated [22]. Thus, the polarized expression of key adhesion molecules remains a viable possibility to explain, in part, the present results with endotoxin.

Pulmonary epithelial cells have been shown to secrete interleukin (IL)-6, IL-8, tumour necrosis factor (TNF)- $\alpha$ and monocyte chemotactic peptide (MCP)-1 when stimulated by endotoxin $[15,29-31]$. The potential importance of sCD14 in endotoxin-induced secretion of IL-8 by pulmonary epithelial cells was demonstrated by PugiN et al. [15]. Several recent studies have also examined the polarized production and secretion of chemoattractants. An apical release of neutrophil chemotactic factors by pulmonary epithelial cells stimulated by endotoxin and $\mathrm{Pseu}$ domonas products, respectively, has been demonstrated $[32,33]$. It should be noted that different lung epithelial cells may have unique responses to endotoxin and other stimuli [7]. Preferential basal to apical migration of neutrophils was evident when alveolar epithelial cells were stimulated apically. The polarized (apical) release of neutrophil chemoattractants by endotoxin-stimulated epithelial cells could either enhance or inhibit transepithelial migration. The failure of neutrophils to migrate when endotoxin was applied above the filters may imply the secretion of neutrophil chemoattractants in a manner obviating a physiologically directed chemotactic gradient [34]. Furthermore, the endotoxin and newly formed chemoattractants could have activated the neutrophils in a nonchemotactic fashion, thus preventing migration across the filters [35]. The present data suggest that the combination of an apical release of neutrophil chemoattractants and a preferential basal to apical directional movement of the neutrophil leads to optimal endotoxin-induced neutrophil transepithelial migration. Thus, there appear to be certain advantages of cellular polarity in mediating inflammatory reactions and immune regulation which allow cells that are properly orientated to respond to positional information inherent to their environment [23].

In summary, these findings demonstrate the importance of the presence and orientation of pulmonary epithelial cells in mediating the extent and location of lung neutrophilic responses due to endotoxin stimulation. Preferential neutrophil migration in a basal to apical direction is likely to be more physiological and may account for the accumulation of neutrophils in the airway lumen subsequent to the inhalation of endotoxin-rich toxicants such as grain dust [36]. A better understanding of such a complex interplay between the endotoxin, pulmonary epithelial cells and neutrophils may allow specific steps to be undertaken to control the destructive inflammatory reactions accompanying endotoxin-induced lung injury.

Acknowledgements: The authors thank E. Carolan, for technical assistance and V. Sears for typing and editorial contribution.

\section{References}

1. Levine SJ. Bronchial epithelial cell-cytokine interactions in airway inflammation. J Invest Med 1995; 43: 241-249.

2. Sibille Y, Reynolds HY. Macrophages and polymorphonuclear neutrophils in lung defense and injury. Am Rev Respir Dis 1990; 141: 471-501.

3. Lukacs NW, Strieter RM, Chensue SW, Widmer M, Kunkel SL. TNF- $\alpha$ mediates recruitment of neutrophils and eosinophils during airway inflammation. J Immunol 1995; 154: 5411-5417.

4. Bittleman DB, Casale TB. Interleukin-8 mediates interleukin $1 \alpha$-induced neutrophil transcellular migration. Am J Respir Cell Mol Biol 1995; 13: 323-329.

5. Smart SJ, Casale TB. Pulmonary epithelial cells facilitate TNF- $\alpha$-induced neutrophil chemotaxis. A role for cytokine networking. J Immunol 1994; 152: 4087-4094.

6. Lieber M, Smith B, Szakal A, Nelson-Rees W, Todaro G. A continuous tumor-cell line from a human lung carcinoma with properties of type II alveolar epithelial cells. Int J Cancer 1976; 17: 62-70.

7. Carolan EJ, Casale TB. Neutrophil transepithelial migration is dependent upon epithelial characteristics. Am J Respir Cell Mol Biol 1996; 15: 224-231.

8. Casale TB, Abbas MK, Carolan EJ. Degree of neutrophil chemotaxis is dependent upon the chemoattractant end barrier. Am J Respir Cell Mol Biol 1992; 7: 112-117.

9. Ferrante A, Thong YH. A rapid one-step procedure for purification of mononuclear and polymorphonuclear leukocytes from human blood using a modification of the Hypaque-Ficoll technique. J Immunol Methods 1978; 24: 389-393.

10. Gallin JI, Clark RA, Kimball HR. Granulocyte chemotaxis: an improved in vitro assay employing ${ }^{51} \mathrm{Cr}$-labeled granulocytes. J Immunol 1973; 110: 233-240.

11. Michel O, Duchateau J, Sergysels R. Effect of inhaled endotoxin on bronchial reactivity in asthmatic and normal subjects. J Appl Physiol 1989; 66: 1059-1064.

12. van Deventer SJH, Buller HR, ten Cate JW, Sturk A, Pauw W. Endotoxaemia: an early predictor of septicaemia in febrile patients. Lancet 1988; i: 605-609.

13. Flaherty DK, Deck FH, Cooper J, et al. Bacterial endotoxin isolated from a water spray air humidification system 
as a putative agent of occupation-related lung disease. Infect Immun 1984; 43: 206-212.

14. Siraganian RP, Baer H, Hochstein HD, May JC. Allergenic and biologic activity of commercial preparations of house dust extract. J Allergy Clin Immunol 1979; 64: 526-533.

15. Pugin J, Schurer-Maly C-C, Leturcq D, Moriarty A, Ulevitch RJ, Tobias PS. Lipopolysaccharide activation of human endothelial and epithelial cells is mediated by lipopolysaccharide-binding protein and soluble CD14. Proc Natl Acad Sci USA 1993; 90: 2744-2748.

16. Wright SD. CD14 and innate recognition of bacteria. $J$ Immunol 1995; 155: 6-8.

17. Weersink AJL, Van Kessel KPM, Van Der Tol ME, Verhoef J. Modulation of lipopolysaccharide binding to human granulocytes. Immunology 1994; 83: 617-623.

18. Hailman E, Lichenstein HS, Wurfel MM, et al. Lipopolysaccharide (LPS)-binding protein accelerates the binding of LPS to CD14. J Exp Med 1994; 179: 269-277.

19. Martin TR, Mathison JC, Tobias PS, et al. Lipopolysaccharide binding protein enhances the responsiveness of alveolar macrophages to bacterial lipopolysaccharide. $J$ Clin Invest 1992; 90: 2209-2219.

20. Tobias PS, Mathison J, Ulevitch RJ. Participation of lipopolysaccharide-binding protein in lipopolysaccharide-dependent macrophage activation. Am J Respir Cell Mol Biol 1992; 7: 239-245.

21. Holter JF, Weiland JE, Pacht ER, Gadek JE, Davis WB. Protein permeability in the adult respiratory distress syndrome. Loss of size selectivity of the alveolar epithelium. J Clin Invest 1986; 78: 1513-1522.

22. Le Gall AH, Yeaman C, Boulan ER. Epithelial cell polarity: new perspectives. Semin Nephrol 1995; 15: 272-284.

23. Eaton S, Simons K. Apical, basal, and lateral cues for epithelial polarization. Cell 1995; 82: 5-8.

24. Eckmann L Kagnoff MF, Fierer J. Epithelial cells secrete the chemokine interleukin- 8 in response to bacterial entry. Infect Immun 1993; 61: 4569-4574.

25. Agace W, Hedges S, Andersson U, Andersson J, Ceska M, Svanborg C. Selective cytokine production by epithelial cells following exposure to Escherichia coli. Infect Immun 1993; 61: 602-609.

26. Zeillemaker AM, Mul FPJ, Hoynck Van Papendrecht AAGM, et al. Polarized secretion of interleukin- 8 by human mesothelial cells: a role on neutrophil migration. Immunology 1995; 84: 227-232.

27. Simon RH, Paine III R. Participation of pulmonary alveolar epithelial cells in lung inflammation. J Lab Clin Med 1995; 126: 108-118.

28. Barton WW, Wilcoxen S, Christensen PJ, Paine R. Disparate cytokine regulation of ICAM-1 in rat alveolar epithelial cells and pulmonary endothelial cells in vitro. Am J Physiol 1995; 269 (Lung Cell Mol Physiol 13): L127L135.

29. Khair OA, Devalia JL, Abdelaziz MM, Sapsford RJ, Tarraf H, Davies RL. Effect of Haemophilus influenzae endotoxin on the synthesis of IL-6, IL-8, TNF- $\alpha$ and expression of ICAM-1 in cultured human bronchial epithelial cells. Eur Respir J 1994; 7: 2109-2116.

30. Paine III R, Rolfe MW, Standiford TJ, Burdick MD, Rollins BJ, Strieter RM. MCP-1 expression by rat type II alveolar epithelial cells in primary culture. $J$ Immunol 1993; 150: 4561-4570.

31. Standiford TJ, Kunkel SL, Basha MA, et al. Interleukin-8 gene expression by a pulmonary epithelial cell line. A model for cytokine networks in the lung. J Clin Invest 1990; 86: 1945-1953.

32. Koyama S, Rennard SI, Leikauf GD, et al. Endotoxin stimulates bronchial epithelial cells to release chemotactic factors for neutrophils. J Immunol 1991; 147: 4293 4301.

33. Inoue H, Massion PP, Ueki IF, et al. Pseudomonas stimulates interleukin-8 mRNA expression selectively in airway epithelium, in gland ducts, and in recruited neutrophils. Am J Respir Cell Mol Biol 1994; 11: 651-663.

34. Colgan SP, Parkos CA, Delp C, Arnaout MA, Madara JL. Neutrophil migration across cultured intestinal epithelial monolayers is modulated by epithelial exposure to IFN- $\gamma$ in a highly polarized fashion. J Cell Biol 1993; 120: 785798.

35. del Pozo MA, Sánchez-Mateos P, Sánchez-Madrid F. Cellular polarization induced by chemokines: a mechanism for leukocyte recruitment? Immunol Today 1996; 17: 127-131.

36. Milanowski J, Sorenson WG, Lewis DM, Dutkiewicz J. Chemotaxis of alveolar macrophages and neutrophils in response to microbial products derived from organic dust. J Invest Allergol Clin Immunol 1995; 5: 221-227. 